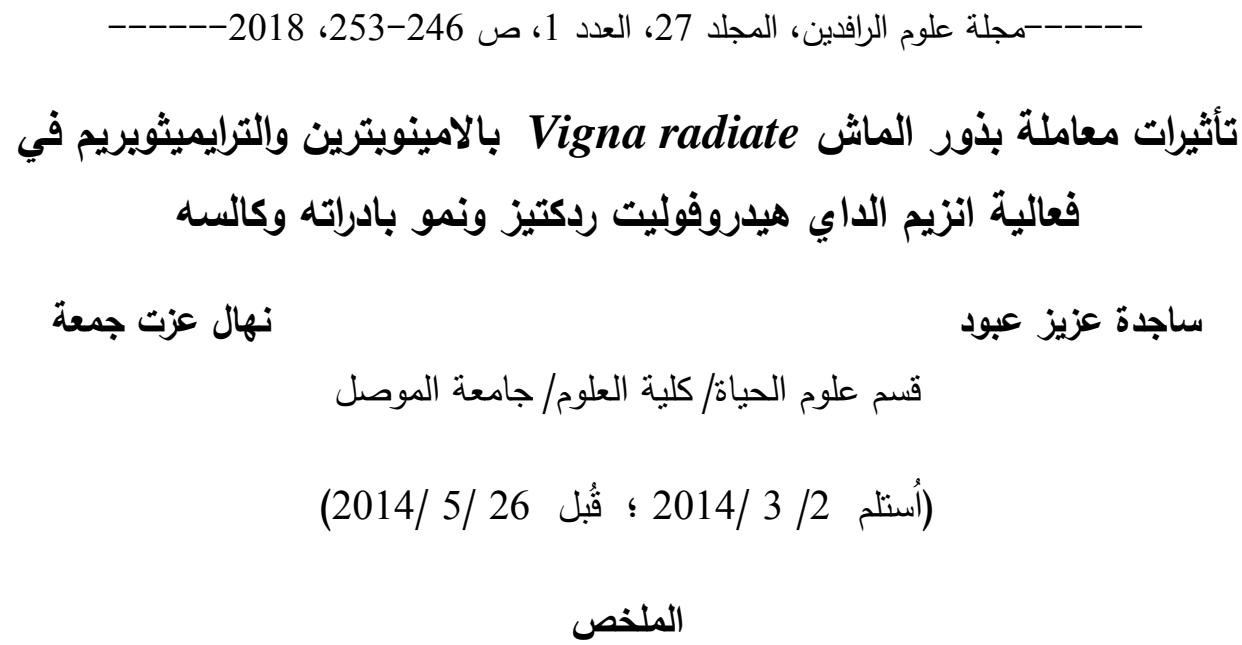

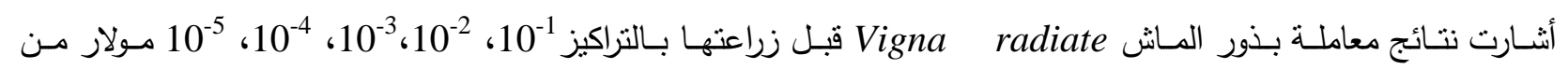

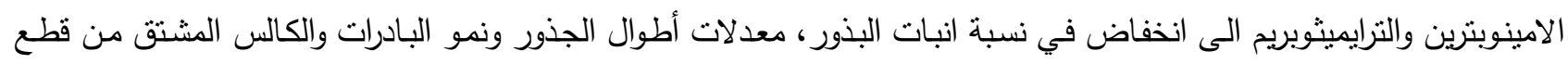

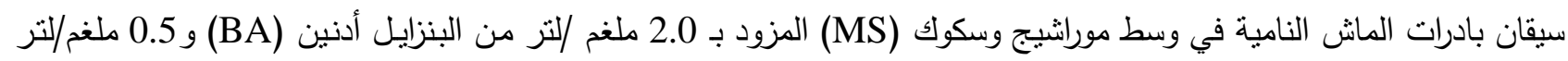

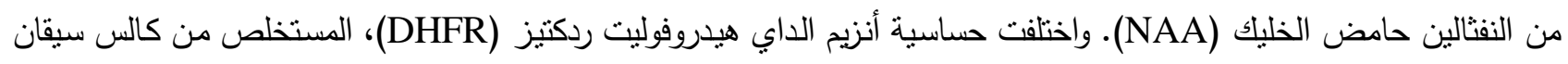

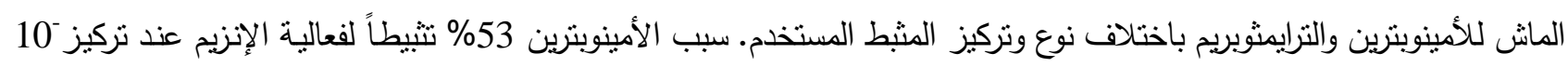

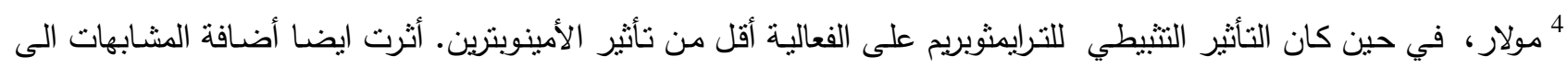

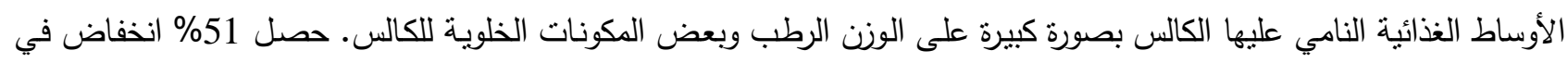

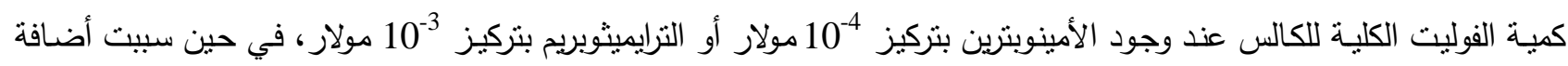

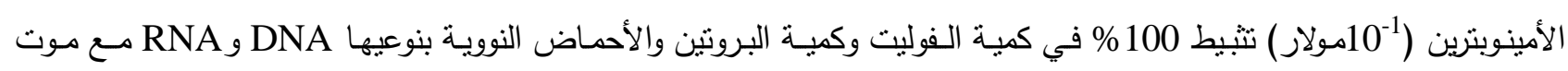

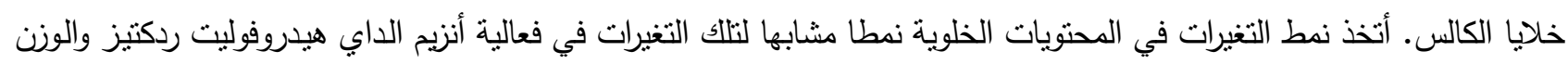
الرطب للكالس.

الكلمات الدادة: كالس الماش، الامينوبترين، التزايميثوبريم، الداي هيدروفوليت ردكتيز.

\title{
Effects of Vigna radiate Seeds Treatment by Aminoptrine and Trimethoprim in the Activity of Dihydrofolate Reductase Enzyme and its Seedlings, Calli Growth
}

\author{
Nihal E. Al - Taee \\ Department of Biology/ College of Science/ University of Mosul
}

\begin{abstract}
The results of Vigna radiate seeds treatment before planting with aminoptrine and trimethoprim at $10^{-1}, 10^{-2}, 10^{-3}, 10^{-4}$ and $10^{-5}$ molar to decrease in the rate of germination, average length of roots and growth of seedlings and calli derived from Vigna radiate seedling segments that grown on Murashige and Skoog (MS) medium supplement with $2.0 \mathrm{mg} / \mathrm{l}$ benzyladenine (BA) and $0.5 \mathrm{mg} / 1$ naphthalene acidic acid (NAA). The sensitivity of DHFR, isolated from Vigna radiate callus, to aminoptrine or trimethoprim varied depending on the type and concentrations of inhibitor used. Aminoptrine caused 53\% inhibition of DHFR at $10^{-4} \mathrm{M}$, however the inhibitory effect of trimethoprim on DHFR was less than that of aminoptrine.

Also addition of inhibitors to the media greatly affected the fresh weight and other cell constituents. There was a $51 \%$ decrease in the total folate content in the presence of $10^{-4} \mathrm{M}$
\end{abstract}


aminoptrine or $10^{-3} \mathrm{M}$ trimethoprim. Addition of aminoptrine at $10^{-1} \mathrm{M}$ caused a $100 \%$ inhibition in the folate, proteins, nucleic acids content and callus death after 30 days of growth.

The pattern of changes in cell constituents of callus grown on media with inhibitors was similar to that of DHFR activity and fresh weight of callus.

Keywords: Vigna radiate callus, Aminoptrin, Trimethoprime, Dihydrofolate reductase.

\section{المقدمة}

تساهم المساعدات الأنزيمية لحامض الفولك من التتراهيدروفوليت في نقل وحدات حاويـة ذرة كربون واحدة مثل المنيلين والمثيل والفورمايل، وتشترك في العديد من التقاعلات الحيوية لبناء الأحماض النووية (Basset et al., 2005) والبروتينات في جسم الكائن الحي (عبود وعزت، 2011). إن نقصان أو تنبيط تكوين تلك المساعدات الأنزيمية يؤدي الى التأثير في هذه الوظائف الحياتية وتثبيطها. يعد الأمينوبترين والترايميثبريم من مشابهات الفوليت اللذين يعمالن على تثبيط فعالية انزيم الدابي هيدروفوليت

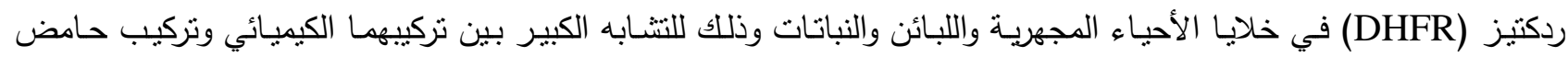

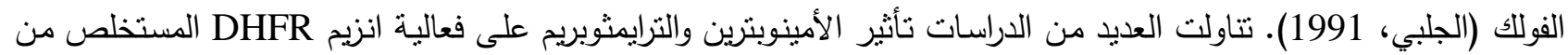
خلايا الأحياء المجهرية واللبائن (Elshaer et al., 2012; Hyaun et al., 2012 ; Vilcheze and Jacob, 2012)، وقلة تلالك التي درست تأثنرهما في فعالية الأنزيم المستخلص من الخلايا النباتية، فقد درس تاثير الأمينوبنرين على نمو بادرات البازلاء

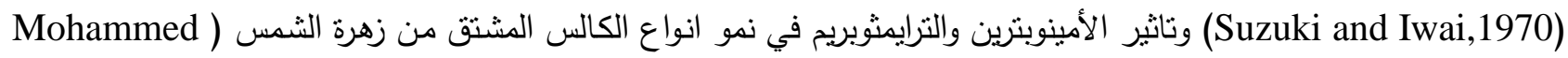

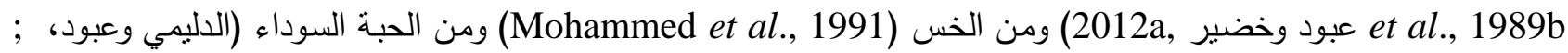
2006b 2008 عبود، 2008 (in)

افترضت الدراسة الحالية، لقلة المعلومات المتوفرة عن أيض حامض الفوللك ودوره في نمو نباتات كالس الماش، في دراسة وفهم بعض الجوانب المتعلقة بأيض الفوليت ودوره في توظيف بناء الأحماض النووية والبروتينات وعلاقتها بالانقسام والنمو لخلايا الكالس، بصورة غير مباشرة من خلال استخدام مشابهات الفوليت كالأمينوبترين والترايمثوبريم المثبطة لعملية بنائها.

\section{المواد وطرائق العمل}

اختبارات تأثير مشابهات الفوليت في انبات البذور

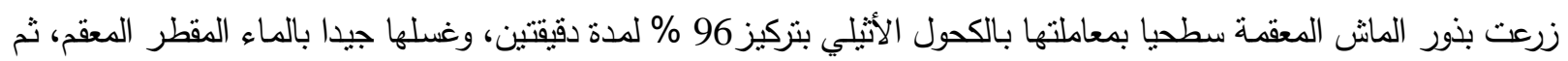

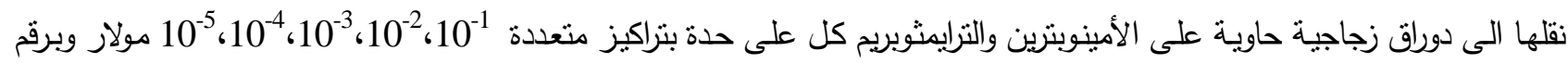

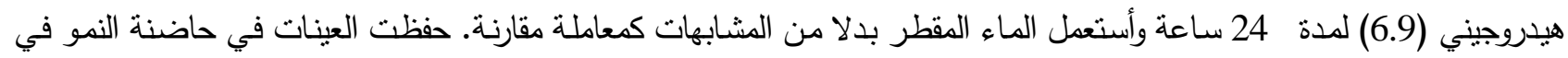
ظروف الظلام وحرارة 25 25 م، غلت البذور بالماء المقطر المعقم عدة مرات، ثم وضعت في أطباق بتري حاوية على أوراق ترشيح

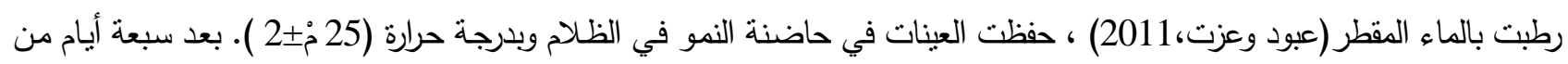
الزراعة حسبت نسبة الأثبات وطول الجذور للبادرات النامية. اختبارات تأثير مشابهات الفوليت في نمو الكالس

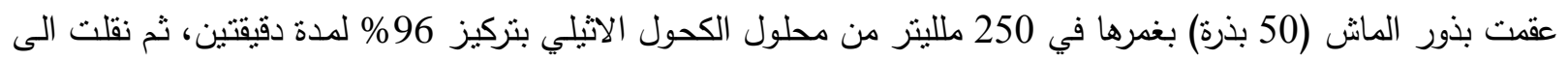

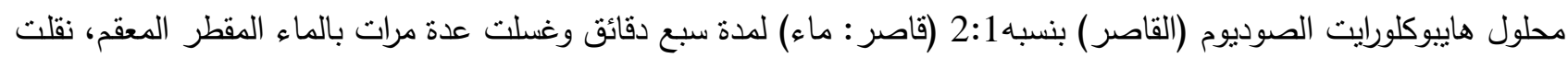
البذور المعقـة الى دوارق زجاجيـة حاويـة على وسط Arnon (Arnon and Hoagland, 1944) المعقم وحضنت البذور 
المزروعة في الظلام في حاضنة النمو وبدرجة حرارة 25د2 لحين بزوغ الجذير، نقلت البذور النامية الى حاضنة النمو المجزة بالضوء بشدة إضاءة 1500 لوكس وبتعاقب بومي لمدة 16 ساعة إضاءة و 8 ساعة ظلام للحصول على البادرات المعقمة.

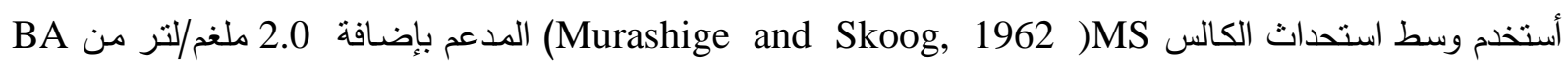
و 0.5 ملغم/ لتر من NAA (عبد الرزاق، 2012) اذ وضعت قطع السيقان المستأصلة من بادرات الماش بعمر 20 يوما وبأطوال

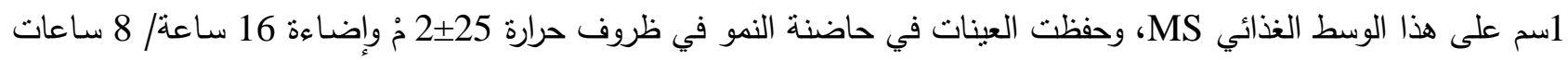

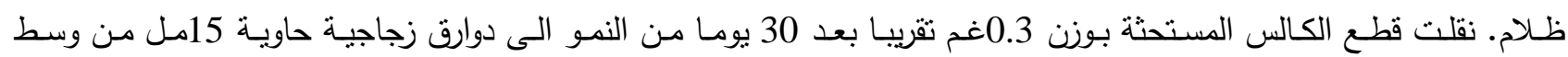
الاستحداث ذاته ومدعما بإضافة التراكيز من 1-10-10-5 مولار من الامينوبترين او الترايميثوبريم بصورة منفصلة. تقدير الاوزان الرطبة للكالس ومحتواه البروتيني

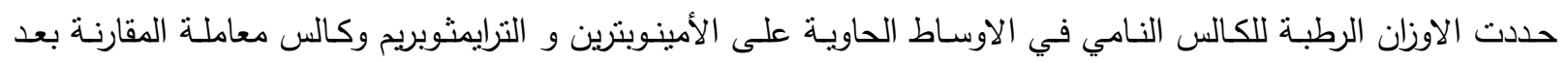
مضي فترة 30 يوما من النمو على تلك الأوساط الغذائية. استخدمت طريقة لاوري (Lowry et al.,1951) في تقدير كمية البروتينات الكلية في الكالس المشتق من سيقان الماش.

تقدير كمية الأحماض النووية الكلية

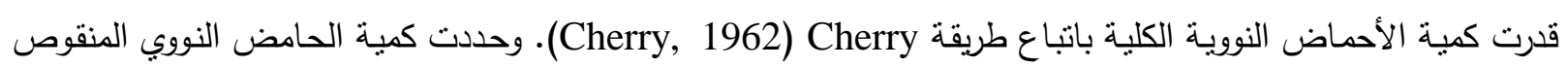
الأوكسجين (DNA)) حسب طريقة Gayer, Giles) (Giles and Mayer, 1967)، ومن حساب الفرق بين الكمية الكلية

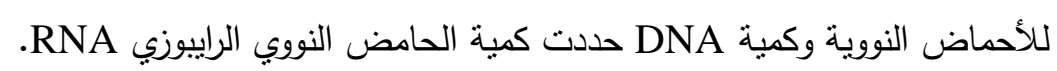
المحتوى الكلي للقوليت استخدمت الطريقة المايكروبايولوجية (AOAC, 1950) في تقدير كمية الفوليت الكلية لكالس سيقان الماش.

تقدير الفعالية النوعية لإنزيم الداي هيدروفوليت رديكتيز (DHFR)

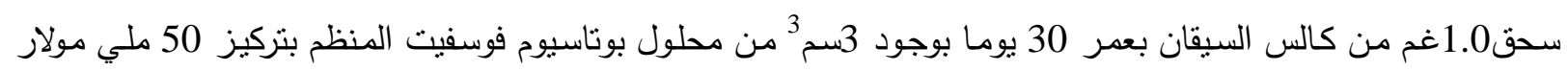
(pH 7)

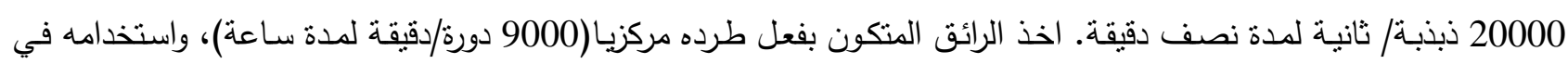
قياس فعالية الانزيم. قيست فعالية أنزيم DHFR من الانخفاض الحاصل في الامتصاص الضوئي لمحلول التفاعل عند الطول الموجي 340 نانوميتز (Osborn and Huennekens, 1958) مع بعض التحويرات (عبود، 1997). يتكون محلول التفاعل بحجم نهائي 3سم3 من 40 ملي مولار من محلول البوتاسيوم فوسفيت المنظم برقم هيدروجيني 6.6، 0.6 مل 0.15 ملي مولار من الداي هيدروفوليت،

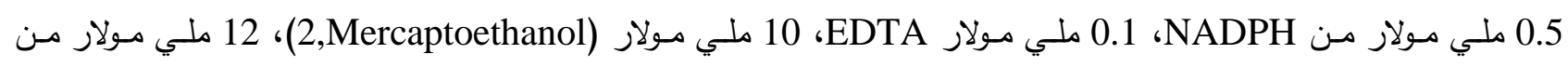
Mgso 4 النتائج

تأثير مشابهات الفوليت في نمو البادرات يثير الجدول (1) الى ان المعاملة المسبقة لبذور نبات الماش بتراكيز من مشابهات الفوليت المستخدمة قبل زراعتها ادى الفى

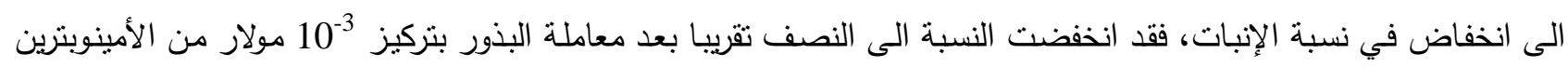
و 2010 مولار من الترايمينوبريم، وحصل ايضا انخفاض واضح في معدل أطوال الجذور بعد مدة نمو 8 أيام مقارنة بمعدل أطوال الجذور للبادرات النامية من بذور معاملة بالماء المقطر فقط (معاملة المقارنة). 
الجدول 1: نسـب انبـات بذور المـاش Vigna radiate المعاملـة بتراكيز مختلفـة مـن الامينـويترين والترايميثويريم واطوال جذورها بعد ثمانية ايام من النمو

\begin{tabular}{|c|c|c|c|}
\hline معدل أطوال الجذور(سم) & نسبة الانبات(\%) & التراكيز (مولار) & مشابهات الفوليت \\
\hline $\mathbf{1 . 8 0} \mp 0.30$ & 80 & $10^{-5}$ & \multirow{5}{*}{ الأمينوبترين } \\
\hline $1.30 \mp 0.11$ & 75 & $10^{-4}$ & \\
\hline $\mathbf{0 . 8 5} \mp 0.02$ & 50 & $10^{-3}$ & \\
\hline $\mathbf{0 . 5 2} \mp 0.02$ & 40 & $10^{-2}$ & \\
\hline 0 & 0 & $10^{-1}$ & \\
\hline 1.95干 0.80 & 90 & $10^{-5}$ & \multirow{5}{*}{ الترايميثوبريم } \\
\hline $\mathbf{1 . 5 5} \bar{\mp} 0.32$ & 80 & $10^{-4}$ & \\
\hline $\mathbf{0 . 9 3 \mp} 0.24$ & 70 & $10^{-3}$ & \\
\hline $\mathbf{0 . 6 5} \mp 0.11$ & 50 & $10^{-2}$ & \\
\hline $\mathbf{0 . 4 5} \mp 0.03$ & 30 & $10^{-1}$ & \\
\hline $2.5 \mp 0.61$ & 100 & ماء مقطر & معاملة المقارنة \\
\hline
\end{tabular}

كل قيمة تمتل معدل عشرة قراءات، بمثل الخطأ القياسي.

تأثير مشابهات الفوليت في الاوزلان الرطبة للكالس تثتير بيانات الجدول (2) الى اختلاف معدل الوزن الرطب باختلاف تركيز مشابهات الفوليت المضافة الى الأوساط الغذائية ونوعيتها. وأدى التركيز 1-10 مولار من الأمينوبترين والترايميثوبريم الى موت معظم نسيج الكالس وتحوله الى اللون البني مقارنة بالكالس الهش ذي اللون الأخضر النامي على الأوساط الغذائية الخالية من مشابهات الفوليت (معاملة المقارنة).

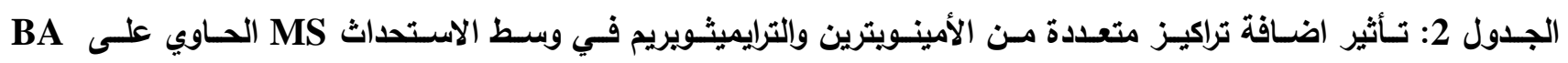

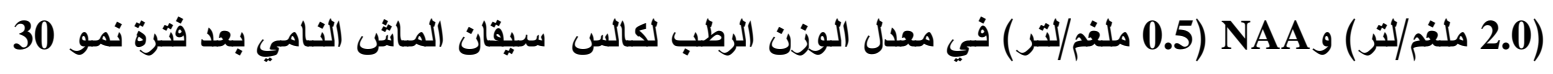

\begin{tabular}{|c|c|c|c|}
\hline & & & يوما \\
\hline الانخفاض الحاصل في الوزن الطري (\%) & معدل الوزن الطري (غرام) & التركيز (مولار) & مشابهات الفوليت \\
\hline 39 & $0.321 \mp \mathbf{3 . 5 2 1}$ & $10^{-5}$ & \multirow{5}{*}{ الأمينوبترين } \\
\hline 56 & $0.232 \mp 2.550$ & $10^{-4}$ & \\
\hline 86 & $0.201 \mp \mathbf{0 . 7 8 6}$ & $10^{-3}$ & \\
\hline 93 & $0.133 \mp 0.405$ & $10^{-2}$ & \\
\hline 100 & - & $10^{-1}$ & \\
\hline 63 & $0.121 \mp 3.700$ & $10^{-5}$ & \multirow{5}{*}{ الترايميثوبريم } \\
\hline 74 & $0.213 \mp \mathbf{3 . 0 8 8}$ & $10^{-4}$ & \\
\hline 76 & $0.341 \mp \mathbf{1 . 3 9 3}$ & $10^{-3}$ & \\
\hline 93 & $0.221 \mp \mathbf{0 . 4 3 3}$ & $10^{-2}$ & \\
\hline 95 & $0.087 \mp \mathbf{0 . 3 0 1}$ & $10^{-1}$ & \\
\hline 0 & $0.221 \mp \mathbf{5 . 8 0 0}$ & \multicolumn{2}{|c|}{ معاملة المقارنة (ماء مقطر) } \\
\hline
\end{tabular}

كل قيمة تمثل معدل عشرة قراءات، ج يمنل الخطأ القياسي، - موت خلايا الكالس.

تأثير مشابهات الفوليت في الفعالية النوعية لا نزيم DHFR

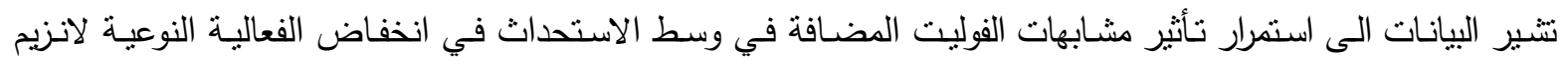
الى النصف تقريبا عند اضافة 4-10 مولار من الأمينوبترين و $10^{-3}$ مولار من الترايميثوبريم الى الوسط، لوحظ زيادة 
التثبيط مع زيادة تركيز المشابهات المضافة الى تلك الأوساط، في حين سبب اضافة كل من الامينوبترين والترايميثوبريم بتركيز 10 مولار الى نظام التفاعل الى تثيط فعالية الانزيم بنسبة 100\% (الجدول 3) 3.

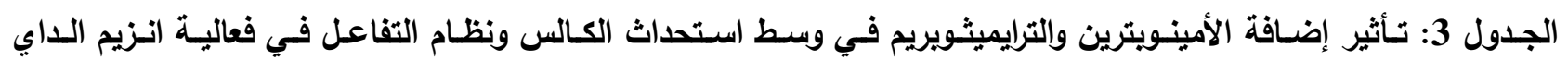
هيدرفوليت ردكتيز المستخلص من كالس سيقان الماش بعمر 30 يوما(In vivo) و(In vitro)

\begin{tabular}{|c|c|c|c|c|c|}
\hline \multicolumn{5}{|c|}{ الفعالية النوعية لإنزيم DHFR (مايكروغرام/دقيقة/ملغرام بروتين) } & \multirow{2}{*}{ 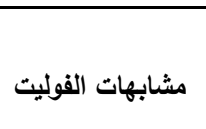 } \\
\hline التثبيط (\%) & In vitro & التثبط (\%) & In vivo & التركيز (مولار) & \\
\hline 41 & $0.212 \mp \mathbf{3 0 . 6 5}$ & 24 & $0.321 \mp \mathbf{4 0 . 2 1}$ & $10^{-5}$ & \multirow{5}{*}{ الأمينوبترين } \\
\hline 63 & $0.342 \mp \mathbf{1 9 . 5 2}$ & 53 & $0.421 \mp 27.12$ & $10^{-4}$ & \\
\hline 88 & $0.444 \quad$ 干 6.31 & 63 & $0.221 \mp 19.81$ & $10^{-3}$ & \\
\hline 97 & $0.322 \mp 1.51$ & 93 & $0.432 \mp 4.16$ & $10^{-2}$ & \\
\hline 100 & 0 & 98 & $0.213 \overline{7} \mathbf{1 . 0 0}$ & $10^{-1}$ & \\
\hline 38 & $0.431 \mp \mathbf{3 2 . 3 5}$ & 20 & $0.323 \mp 40.12$ & $10^{-5}$ & \multirow{5}{*}{ التزايميشريم } \\
\hline 48 & $0.215 \mp 27.03$ & 39 & $0.222 \bar{\mp} 32.51$ & $10^{-4}$ & \\
\hline 78 & $0.253 \mp \mathbf{1 1 . 3 6}$ & 52 & $0.331 \mp 25.55$ & $10^{-3}$ & \\
\hline 92 & $\bar{\mp} 0.3334 .26$ & 88 & $0.212 \mp 7.21$ & $10^{-2}$ & \\
\hline 100 & 0 & 97 & $0.233 \mp 2.31$ & $10^{-1}$ & \\
\hline 0 & $0.565 \mp \mathbf{5 2 . 2 2}$ & 0 & $0.326 \mp \mathbf{5 3 . 1 2}$ & & معاملة المقارنة (ماءعقة \\
\hline
\end{tabular}

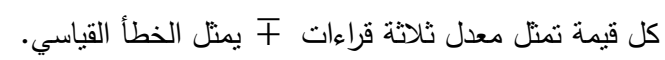
* الفعالية النوعية للإنزيم: كمية الانزيم اللازمة لاكسدة مايكرومول واحد من NADPH خلال دقيقة واحدة من التفاعل لكل ملغغ بروتين.

تأثير مشابهات الفوليت في المحتوى البروتين الكلي للكالس

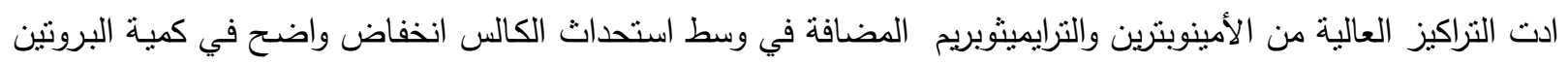
الكلية للكالس بعد 30 يوما من النمو (الجدول 4).

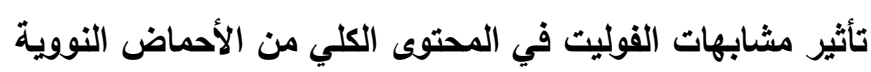

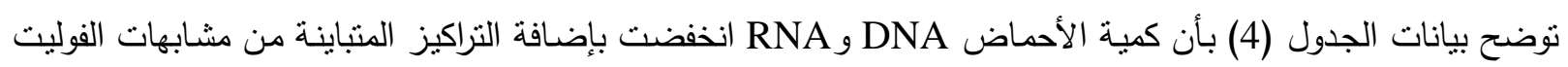
وخصوصا اضافة التركيز 10 $10^{-1}$ مولار من الأمينوبترين والنترايميثوبريم.

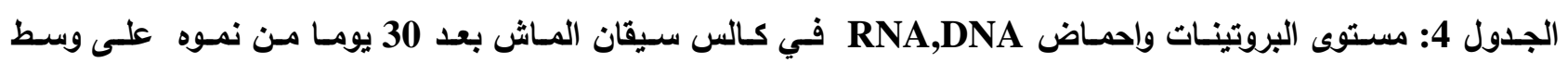
الاستحداث MS المدعم بـ BA (2.0ملفم /لتر) وNAA (0.5 ملفم/تتر) بوجود تراكيز متعددة من مشـابهات الفوليت

\begin{tabular}{|c|c|c|c|c|}
\hline 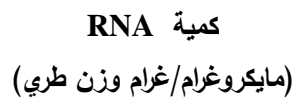 & كمية DNA (مايكروغرام/غرام وزن & 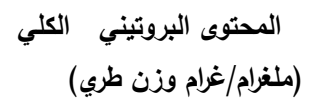 & التركيز (مولار) & مشابهات الفوليت \\
\hline $0.546 \mp \mathbf{1 0 8 . 1 0}$ & $0.321 \mp \mathbf{1 2 . 0 1}$ & $0.032 \mp \mathbf{0 . 8 0 1}$ & $10^{-5}$ & \multirow{5}{*}{ الامينوبترين } \\
\hline $0.453 \mp 97.08$ & $0.324 \mp \mathbf{1 1 . 0 3}$ & $0.022 \mp \mathbf{0 . 7 2 2}$ & $10^{-4}$ & \\
\hline $0.545 \mp \mathbf{8 4 . 1 5}$ & $0.222 \mp 8.41$ & $0.111 \mp \mathbf{0 . 5 0 3}$ & $10^{-3}$ & \\
\hline $0.323 \mp \mathbf{5 9 . 0 0}$ & $0.321 \mp 6.21$ & $0.035 \mp \mathbf{0 . 2 2 8}$ & $10^{-2}$ & \\
\hline- & - & - & $10^{-1}$ & \\
\hline $0.332 \mp \mathbf{1 3 2 . 2 4}$ & $0.111 \mp \mathbf{1 3 . 2 4}$ & $0.232 \mp \mathbf{1 . 0 8}$ & $10^{-5}$ & \multirow{4}{*}{ التزايميثوبريم } \\
\hline $0.434 \mp \quad \mathbf{1 2 8 . 1 0}$ & $0.121 \mp \mathbf{1 2 . 2 0}$ & $0.077 \mp \mathbf{0 . 9 3}$ & $10^{-4}$ & \\
\hline $0.457 \mp \mathbf{1 1 1 . 9 3}$ & $0.432 \mp \mathbf{1 1 . 4 2}$ & $0.088 \mp \mathbf{0 . 8 3}$ & $10^{-3}$ & \\
\hline $0.099 \mp 79.93$ & $0.333 \mp \mathbf{8 . 9 8}$ & $0.055 \mp \mathbf{0 . 5 6}$ & $10^{-2}$ & \\
\hline
\end{tabular}




\begin{tabular}{|c|c|c|c|c|}
\hline $0.321 \mp \mathbf{3 3 . 5 6}$ & $0.121 \mp \mathbf{3 . 3 5}$ & $0.011 \mp \mathbf{0 . 3 2}$ & $10^{-1}$ & \\
\hline $0.221 \mp \mathbf{1 8 8 . 3 1}$ & $0.545 \mp \mathbf{2 2 . 9 9}$ & $0.121 \mp \mathbf{2 . 5 3}$ & (معاملة المقارنة(ماءمقطر) \\
\hline
\end{tabular}

كل قيمة تثثل معدل ثلاثة قراءات، $\mp$ ج الخطأ القياسي

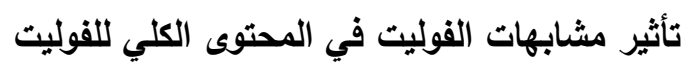

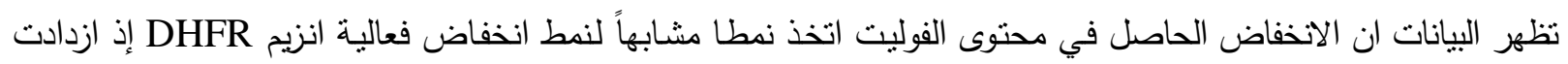
نسب التتبيط بإضافة الامينوبترين والترايميثوبريم مع زيادة تراكيزهما في الأوساط الغذائية النامي عليها الكالس (الجدول 5. 5).

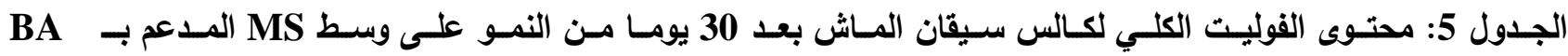
(2.0 ملفم /لتر) وNAA (0.5 ملفم/لتر) وتراكيز متعددة من مشابهات الفوليت

\begin{tabular}{|c|c|c|c|}
\hline للانذفاض(100\%) & كمية الفوليت الكلية مايكروغرام /غرام وزن & التراكيز (مولار) & مثابهات الفوليت \\
\hline 40 & $0.078 \mp \mathbf{1 . 2 2 2}$ & $10^{-5}$ & \multirow{5}{*}{ الأمينوبترين } \\
\hline 51 & $0.333 \mp 0.995$ & $10^{-4}$ & \\
\hline 74 & $0.002 \mp \mathbf{0 . 5 3 2}$ & $10^{-3}$ & \\
\hline 98 & $0.055 \mp \mathbf{0 . 2 2 5}$ & $10^{-2}$ & \\
\hline 100 & - & $10^{-1}$ & \\
\hline 35 & $0.421 \mp \mathbf{1 . 3 1 2}$ & $10^{-5}$ & \multirow{5}{*}{ الترايميثوبريم } \\
\hline 45 & $0.300 \mp \mathbf{1 . 1 1 1}$ & $10^{-4}$ & \\
\hline 51 & $0.121 \mp \mathbf{0 . 7 3 2}$ & $10^{-3}$ & \\
\hline 78 & $0.065 \mp \mathbf{0 . 4 4 3}$ & $10^{-2}$ & \\
\hline 90 & $0.031 \mp \mathbf{0 . 2 0 0}$ & $10^{-1}$ & \\
\hline 0 & $0.400 \mp \mathbf{2 . 0 3 1}$ & \multicolumn{2}{|c|}{ معاملة المقارنة (ماء مقطر ) } \\
\hline
\end{tabular}

كل قيمة تمنلك معدل ثلاثة قراءات، َ يمثل الخطأ القياسي.

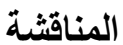

ان عدم حصول انبات البذور عند التراكيز العالية من الأمينوبترين والترايميثوبريم ، قد يعزى الى المستويات المرتفعة من

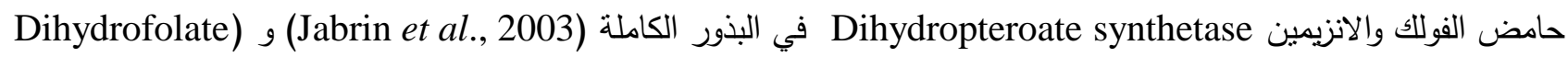
(Suzuki and Iwai,1970) (reductase)، اذ ان تشرب البذور بالماء يحفز الانزيمات لبناء مركبات الفوليت الضرورية لإنبات

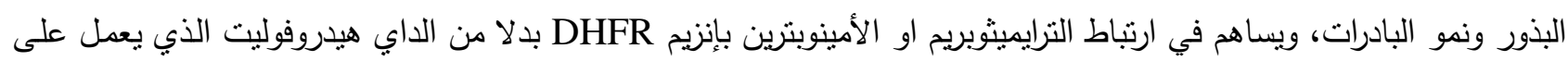

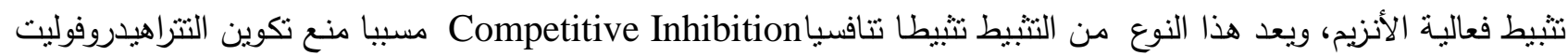

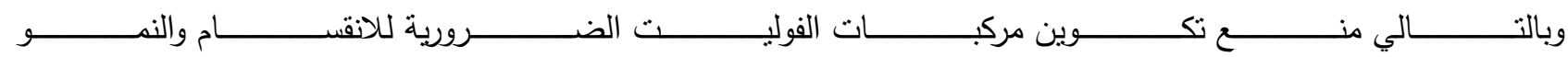
(Hyaun et al., 2012). ومن المحتمل ان يفسر الانخفاض في المحتويات الخلويـة للكالس الى تثبط الداب هيدروفوليت وبالتالي تثبيط تكوين التتراهيدروفوليت الذي نتارك مشنقاته في بناء حلقة البيورين بإضافة ذرة الكربون رقم 2 و 8 اليها (الجلبي، 1991) وفي بناء نيوكلوتيد الثايمين (الطائي واخرون AAl-Taee et al., 2013; 2013) وادى هذا التأثنير التثبيطي الى لى الانخفاض في كمية DNA وبالتالي انخفاض في كمية RNA التي تعتمد اساسا على كمية DNA الموجود في الخلية (عبود

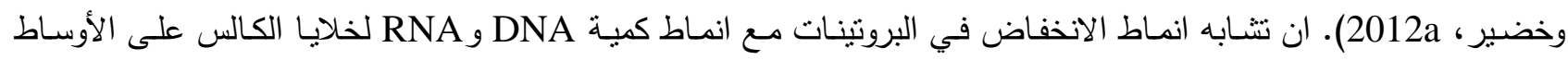
الغذائية الحاوية على الأمينوبترين والترايميثوبريم وان اقتران الانخفاض في البروتينات والأحماض النووية ادى الى انخفاض النيه الوزن

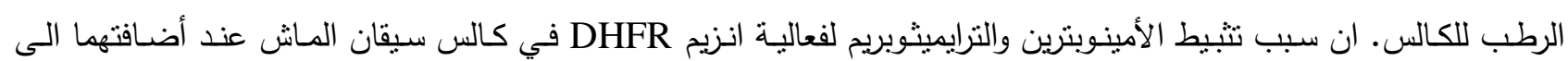


الأوسـاط الغذائيـة بتركيز 1-10 مـولار لكل منهمـا، كـان مهـاثلا لتتبيطهيـا لأنزيم DHFR المستخلص مـن خلايـا كـالس الخس (عبود،1997) وكالس نبات الحبة السوداء (الدليمي وعبود، 2006b) وكالس نبات زهرة الثمس (عبود وخضير، 2012b). ان

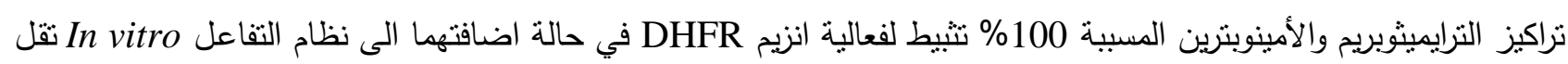

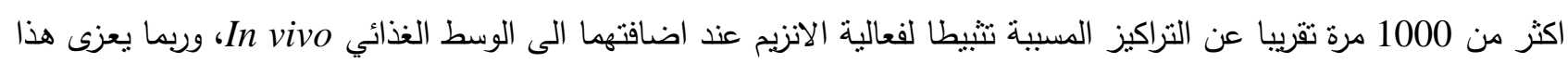
الى انخفاض قابلية امتصاص خلايا الكالس لهذه المشابهات من الوسط الغذائي او الى تحطيم قسم منها داخل الخلايا او وجود نوع من المقاومة لتلك المشابهات داخل الخلايا وان انخفاض فعالية انزيم DHFR خارج النظام (In vitro) وداخل النظام (

(vivo بوجود الترايميثوبريم والأمينويترين يؤكد بان هذه المشابهات متخصصة في تثبيط انزيم Crosti, 1981) DHFR).

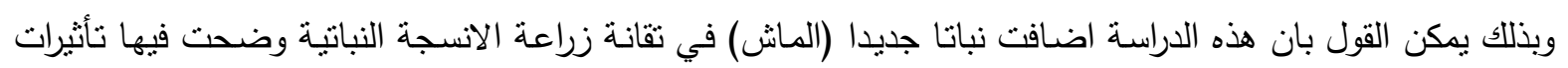

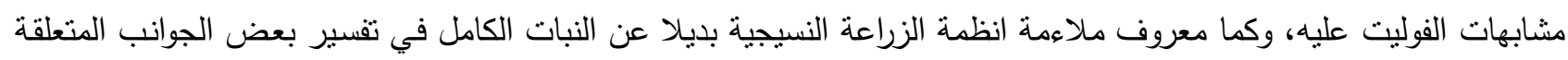

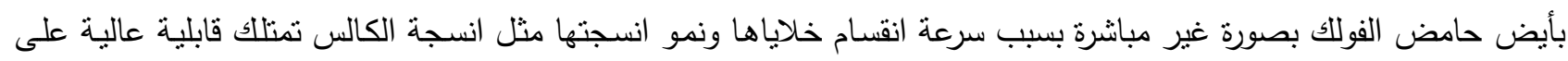

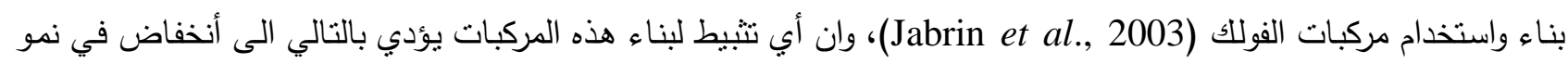
الخلايا او موتها (Ekman, 1982).

\section{المصادر العربية}

الجلبي، قصي عبد القادر (1991). "الاحماض النووية"، دار الكتب للطباعة والنشر ، مطبعة جامعة الموصل، العراق.

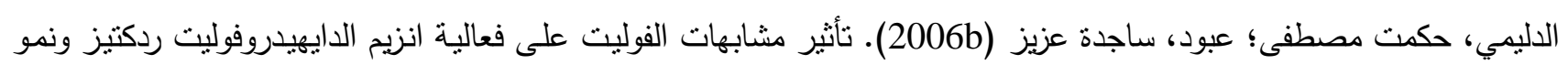

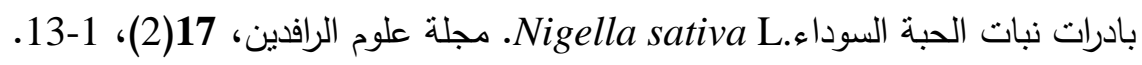

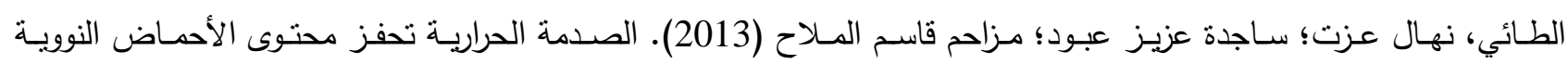
والبروتينات والفعالية النوعية لأنزيمات بناء نيوكليوتيد الثايمين في كالس سيقان السمسم.Sesamum indicum L.

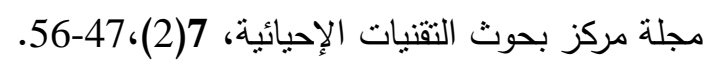

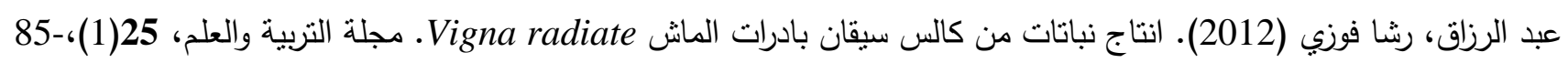
.77

عبود، ساجدة عزيز (1997). دور حامض الفولك في بناء البريمدينات والبيورينات في كالس نبات الخس .Lctuca sativa L.

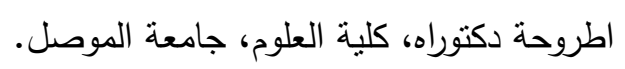

عبود، ساجدة عزيز (2008). تأثير تعريض كالس سيقان نبات الحبة السوداء (igella sativa L. لأثعة كاما على فعالية

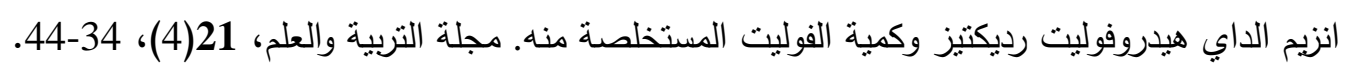

عبود، ساجدة عزيز عبود؛ خضير، فراس حميد (2012a). تأثير الأشعة فوق البنفسية في نمو وتمايز كالوس نبات زهرة الثمس 21-9 (1) مجلة مؤتة للبحوث والدراسات، 27 (Helianthus annuus L.)

عبود، ساجدة عزيز عبود؛ خضير، فراس حميد (2012b). قياس الفعالية النوعية لأنزيم الدابي هيدروفوليت ردكتيز وتقدير كمية

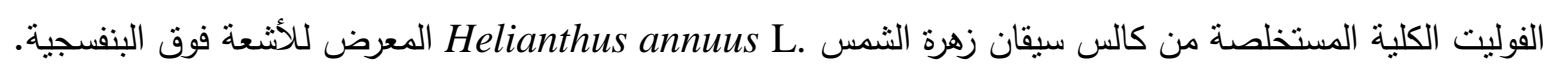

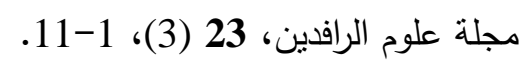
عبود، سـاجدة عزيز ؛ عزت، نهال (2011). تأثثر مركب السلفاسيتامايد في نمو واستحداث كالس سيقان نبات الحبـة السوداء (Nigella sativa L.) 
Al-Taee, N.E.; Abood, A.S.; Al-Mallah, M.K. (2013). Ultrasonic waves stimulate the activity of thymine nucleotide biosynthesis enzymes, Nucleic Acids and Proteins Content of Sesamum indicum L. Stem Calli. Dirasat, Pure Sciences, 39(1), 91-97.

Arnon, D.I.; Hoagland, D.R. (1944). The investigation of plant nutrition by artificial culture methods. Boil. Rev., 9, $55-67$.

Association of Official Agricultural Chemists (1950)."Official Methods of Analysis of the Associations of Official Agricultural Chemists". $7^{\text {th }}$ ed. Washington D.C. 784.

Basset, G.J.C.; Quinlivan, E.P.; Gregory, J.F.; Hanson, A.D. (2005). Folate synthesis and metabolism in plants and properties for biofortication. Crop Sci. Soci. America, 45, 449453.

Cherry, J.H. (1962). Nucleic acid determination in storage tissue of higher plants. Plant Physiol. 37, $670-678$.

Crosti, P. (1981). Effect of folate analogues on the activity of dihydrofolate reductase and on the growth of plant organisms. J. Exp. Bot., 32,717-723.

Ekman, B.T. (1982). Studies on dihydrofolate reductase and trimethoprim resistance in E. coli :Acta Universitatic Upsaliensis, Abstract of Uppsala Dissertation from Faculty of Pharmancy. $1-41$.

Elshaer, A.; Hanson, P.; Worthington, T.; Lambert, P.; Mohammed, A.R. (2012). Preparation and characterization of amino acids -based Trimethoprim salts. Pharmaceutics, 4, 179-196.

Giles, K.W.; Mayer, A. (1967). Determination of DNA concentration with diphenylamine reagent. Method of Enzymol. Academic Press (New York), 12, 163.

Hyaun, S.C.; Obican, S.C.; Scialli, A.R. (2012). Teratogen Update: Methotrexate. Brith Defects Research, 94, 187-207.

Jabrin, S.; Ravanel, S.; Gambonnet, B.; Douce, R.; Rebeillc, F. (2003). One - carbon metabolism in plants, regulation of tetrahydrofolate synthesis during germination and seedling development. Plant Physiol., 131, 1431-1439.

Lowry, O.H.; Rosebrough, N.J.; Faw, A.L.; Randull, R.J. (1951). Protein measurement with Folin phenol reagent. J. Biol. Chem. 193, $265-275$.

Mohammad, A.M.S.; Abood, S.A.; Al-Salih, H.S. (1991). Effect of folate analogous on protein, RNA and DNA contents of lettuce. Iraqi J. Biol. Sci., 11, 5-25.

Mohammed, A.M.S.; Al-Chalabi, K.A.; Abood, S.A. (1989b). Effect of folate analogues on the activity of dihydrofolate reductase and callus growth of Sunflower. J. Exp. Bot., 40, 70-76.

Murashige, I.; Skoog, F. (1962). A revised medium for rapid growth and bioassay with tobacco tissue cultures. Physiol. Plant. 15, 473- 497.

Osborn, M.J.; Huennekens, F.M. (1958). Enzymatic reduction of dihydrofolate reductase. J. Biol. Chem., 233, 969-964.

Suzuki, N.; Iwai, K. (1970). The occurrence and properties of dihydrofolate reductase in pea seedling. Plant and Cell Physiol., 11, 199-208.

Vilcheze, C.; Jacob, J. (2012). The combination of sulfmethoxazole, Trimethoprim and isonizid or rifampin is bactericidal and prevents the emergence of drug resistance in Mycobacterium tuberculosis. Antimicrob Agents Chemother., 56, 5142-5148. 